Reported series of $\mathrm{H}$ pylori infection in patients with Barrett's oesophagus

\begin{tabular}{lcccl} 
& \multirow{2}{*}{$\begin{array}{l}\text { No of } \\
\text { Author (ref) }\end{array}$} & \multicolumn{2}{l}{ H pylori positive } & \\
\cline { 3 - 4 } & patients & Stomach & Barrett's & Diagnostic method \\
\hline Talley $^{2}$ & 23 & & $12(52 \%)$ & Warthin-Starry \\
Paull $^{3}$ & 26 & $10(38 \cdot 4 \%)$ & $4(15 \cdot 4 \%)$ & Giemsa \\
Houck $^{4}$ & 34 & & 0 & Giemsa \\
Fallingborg $^{5}$ & $46^{\mathrm{a}}$ & & $12(26 \%)$ & Culture \\
Walker $^{6}$ & $133^{\mathrm{b}}$ & & $6(4 \cdot 5 \%)$ & Culture \\
Francoual $^{7}$ & 7 & & $2(29 \%)$ & Culture \\
GOSPE $^{8}$ & 11 & $4(44 \cdot 4 \%)$ & 0 & Culture \\
Present series & 100 & & $19(19 \%)$ & Warthin-Starry, Giemsa \\
\hline
\end{tabular}

'Biopsy specimens after gastroscopy.

${ }^{b}$ Biopsy specimens before gastroscopy.

specimens with and without $H$ pylori, both for chronic $(81 \% v 79 \%)$ and acute $(9 \% v 10 \%)$ infiltrates.
Discussion
$H$ pylori infection plays an important role in the aetiopathogenesis of chronic gastritis, duodenal and gastric ulcers, and gastric carcinoma. How- ever, its potential role in Barrett's oesophagus has not been completely defined. The detection rate of the bacteria using different techniques has been reported at between $0 \%$ and $52 \%$ in cases of Barrett's oesophagus, ${ }^{2-8}$ while its presence in the stomach has been reported at between $38 \%$ and $44 \%$ in the same patients (table). ${ }^{37}$ In the present study the frequency of $H$ pylori was low in oesophageal biopsy specimens $(15 \%)$ as well as in gastric biopsy specimens $(35 \cdot 6 \%)$. Specialised metaplastic epithelium was not colonised by the bacteria

and the presence of $H$ pylori in the oesophagus was always associated with gastric infection. This finding has been reported previously in retrospective studies ${ }^{7813}$ indicating that $H$ pylori colonisation of Barrett's mucosa is probably a consequence of gastric infection. We did not find any differences regarding the inflammatory changes in oesophageal biopsy specimens of patients either with or without $H$ pylori. We conclude from our results that $H$ pylori does not play an important role in Barrett's oesophagus; its presence in the metaplastic oesophageal mucosa needs the presence of a gastric-type mucosa in the oesophagus, together with a gastric infection.

1 Paull A, Trier JS, Dalton MD, Camp RC, Loeb P, Goyal RK. The histologic spectrum of Barrett esophagus. N Engl f Med 1976;295:476-80.

2 Talley NJ, Cameron AJ, Shorter RG, Zinsmeister AR, Phillips SF. Campylobacter pylori and Barrett's oesophagus. Mayo Clin Proc 1988;63:1176-80.

3 Paull G, Yardley JH. Gastric and esophageal Campylobacter pylori in patients with Barrett's esophagus. Gastroenterology 1988;95:216-8.

4 Houck JA, Lucas JG. Absence of Campylobacter-like organisms in Barrett's esophagus. Arch Pathol Lab Med 1989; 113:470-2.

5 Fallingborg J, Agnholt J, Moller-Petersen J, Christensen LA, Lomborg S, Sondergaard G, et al. Campylobacter pylori in esophagus. Dig Dis Sci 1989;34:1802-3.

6 Walker SJ, Birch PJ, Stewart M, Stoddard CJ, Hart CA Day DW. Patterns of colonisation of Campylobacter pylori in the oesophagus, stomach and duodenum. Gut 1989; 30:1334-8.

7 Francoual S, Lamy Ph, Le Quintrec Y, Luboinski J, Petit JC. Helicobacter pylori: has it a part in the lesion of the gastroesophageal reflux? F Infect Dis 1990;162:1414.

8 Gruppo Operativo Per Lo Studio Delle Precancerosi Esofagee (GOSPE). Helicobacter pylori in Barrett's oesofagee (GOSPE). Helicobacter pylori

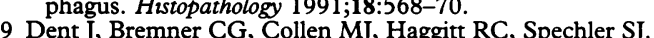
Bent J, Bremner CG, Collen MJ, Haggitt RC, Spechler SJ. Barrett's oesophagus. f Gastroenterol Hepatol 1991;6:1-22.
Andersen LP, Holck S, Poulsen CO. Campylobacter pylori detected by indirect immunohistochemical technique. APMIS 1988;96:559-64.

\title{
Use of buffered formaldehyde in the enzymatic digestion of inflamed mucosa
}

\author{
J Meenan, D O Obradov, H van Dullemen, G N J Tytgat, S J H van Deventer
}

Department of

Gastroenterology and Hepatology, Academic Medical Centre, University of Amsterdam, Amsterdam,

The Netherlands

Correspondence to: Dr J Meenan,

ent of

Gastroenterology and

Hepatology, Academic

Medical Centre,

Meibergdreef 9, $1105 \mathrm{AZ}$

Amsterdam,

The Netherlands.

Accepted for publication

20 July 1995

\begin{abstract}
Mucosal inflammation is associated with altered expression of cell membrane molecules. Disaggregation of tissue for flow cytometry may introduce artefactual changes. In an attempt to prevent the induction of artefacts, cells were fixed prior to isolation. The addition of $0 \cdot 1 \%$ buffered formaldehyde to the collagenase/dispase digestion of mucosal biopsy specimens from patients with inflammatory bowel disease enhances detection of CD3, CD11b, CD16, CD63, and CD14. No significant effect was noted for CD19, CD67 or CD45. The expression of CD3, CD11b and CD45 correlated with the degree of endoscopic inflammation. Dilute buffered
\end{abstract}

Flow cytometry is more flexible than standard immunohistochemistry, both in terms of cell numbers analysed and the combination of antigens examined. However, prior to analysis, tissue samples must be disaggregated by mechanical, ion chelation or enzymatic methods. ${ }^{12}$ 
Density of expression of surface antigens

\begin{tabular}{|c|c|c|c|}
\hline Antigen & Medium only & $B F A$ treated & $p$ value \\
\hline Control & $\begin{array}{l}3 \cdot 2 \\
(1 \cdot 5-7 \cdot 5)\end{array}$ & $\begin{array}{l}4 \cdot 3 \\
(1 \cdot 8-7 \cdot 8)\end{array}$ & 0.02 \\
\hline $\mathrm{CD} 11 \mathrm{~b}$ & $\begin{array}{l}2 \cdot 2 \\
(0 \cdot 0-9 \cdot 1)\end{array}$ & $\begin{array}{l}8 \cdot 4 \\
(1 \cdot 2-65 \cdot 4)\end{array}$ & 0.02 \\
\hline CD54 & $\begin{array}{l}6 \cdot 2 \\
(0.4-16.9)\end{array}$ & $\begin{array}{l}3 \cdot 8 \\
(0 \cdot 0-21 \cdot 0)\end{array}$ & 0.58 \\
\hline CD45 & $\begin{array}{l}3 \cdot 3 \\
(0 \cdot 0-801 \cdot 0)\end{array}$ & $\begin{array}{l}4 \cdot 4 \\
(0 \cdot 2-1070 \cdot 0)\end{array}$ & 0.39 \\
\hline CD3 & $\begin{array}{l}14 \cdot 2 \\
(1.8-23 \cdot 0)\end{array}$ & $\begin{array}{l}30 \cdot 7 \\
(2 \cdot 6-52 \cdot 3)\end{array}$ & 0.02 \\
\hline CD19 & $\begin{array}{l}2 \cdot 4 \\
(0 \cdot 2-25 \cdot 3)\end{array}$ & $\begin{array}{l}3.4 \\
(0.5-19.1)\end{array}$ & 0.24 \\
\hline $\mathrm{CD} 14$ & $\begin{array}{l}1.45 \\
(0.0-3 \cdot 75)\end{array}$ & $\begin{array}{l}4.25 \\
(0.75-10.55)\end{array}$ & 0.04 \\
\hline CD63 & $\begin{array}{l}36 \cdot 8 \\
(1 \cdot 1-80 \cdot 7)\end{array}$ & $\begin{array}{l}55.9 \\
(0.71-136.8)\end{array}$ & 0.06 \\
\hline CD67 & $\begin{array}{l}3 \cdot 3 \\
(0 \cdot 0-43 \cdot 3)\end{array}$ & $\begin{array}{l}1 \cdot 7 \\
(0-55 \cdot 6)\end{array}$ & 0.06 \\
\hline CD16 & $\begin{array}{l}0.41 \\
(0.0-2.65)\end{array}$ & $\begin{array}{l}1 \cdot 86 \\
(0 \cdot 0-12 \cdot 0)\end{array}$ & 0.04 \\
\hline
\end{tabular}

Results are expressed as the median (range) increment in the median logarithmic fluorescence intensity (dMFI) of cells stained with specific antibody compared with the same cells stained with control antibosdy. Significance was set at the $5 \%$ level.

These processes require the prolonged exposure of cells to intemperate conditions. The use of stringent isolation protocols may unduly influence the expression of cellular surface antigens through regulatory changes, shedding of, or alterations to the antigen. ${ }^{3}$

Early fixation, through the incorporation of paraformaldehyde into regimens for processing whole blood preparations, has been reported to prevent altered leucocyte surface antigen expression. ${ }^{4}$ However, the feasibility and benefit of carrying out early antigen fixation before the disaggregation of solid tissue is unknown. The aim of this study was to determine the influence of fixative use, using flow cytometry, on the identification of surface antigens on cells isolated from endoscopic biopsy specimens of inflamed colonic mucosa.

\section{Methods}

MONOCLONAL ANTIBODIES AND REAGENTS

The following monoclonal antibodies were used: Simultest $\operatorname{IgG}_{1}$ and $\operatorname{IgG}_{2}$, anti-CD3, antiCD19, and anti-CD14 (Becton Dickinson, Mountain View, California, USA); antiCD11b, anti-CD16, anti-CD45, anti-CD63, and anti-CD67 (Central Laboratory of The Netherlands Red Cross Blood Transfusion Service (CLB), Amsterdam, The Netherlands); anti-bcl-2 and phycoerythrin conjugated $\mathrm{F}\left(\mathrm{ab}^{\prime}\right) 2$ immunoglobulin rabbit anti-mouse (Dako, Glostrup, Denmark); and anti-CD54 (Monosan, Uden, The Netherlands). Reagents included: collagenase type IV (Sigma, St Louis, Missouri, USA); dispase I (Boehringer-Ingelheim, Mannheim, Germany); and RPMI 1640 culture medium and fetal bovine serum (FBS) (Life Technologies, Paisley, Scotland). Buffered formaldehyde (4\%) (BFA) was prepared freshly in phosphate buffered saline from paraformaldehyde.

TISSUE COLLECTION AND CELL ISOLATION Following informed consent, six endoscopic biopsy specimens were obtained at routine sigmoidoscopy from 27 patients (14 men, 13 women; median age 38 years (range 19-64 years)) with a history of ulcerative colitis. These biopsy specimens were obtained under a protocol approved by the Medical Ethics Committee of the Academic Medical Centre, Amsterdam. The endoscopic appearance of the mucosa was scored according to a modified Baron scale ${ }^{5}$ : grade I $(n=13)$, normal $/ \mathrm{mild}$ inflammation (Baron 0-1); grade II $(n=14)$, moderate/severe inflammation (Baron 2,3). Tissue was equally divided between tubes containing RPMI 1640 medium supplemented with $10 \%$ FBS, with and without (medium only) $0 \cdot 1 \%$ BFA (v/v). Within fifteen minutes, the biopsy specimens were transferred to fresh RPMI/FCS containing collagenase type IV (50 $\mathrm{U} / \mathrm{ml})$ and dispase type $\mathrm{I}(1.2 \mathrm{U} / \mathrm{ml})$. Once again, $0 \cdot 1 \% \mathrm{BFA}$ was added to the appropriate tubes.

The tubes containing the biopsy specimens were set on an inclined rotating table (Multipurpose rotator, Scientific Industries Inc., New York, USA) for one hour at $37^{\circ} \mathrm{C}$. Cells were subsequently washed twice in fresh RPMI 1640/FBS (with or without BFA), pelleted, counted by light microscopy using eosin, and resuspended in phosphate buffered saline containing $0.1 \%$ bovine serum albumin, $0.01 \%$ sodium azide and $0.3 \mathrm{mM}$ EDTA, to a concentration of $2 \times 10^{6}$ cells $/ \mathrm{ml}$.

\section{CELL LABELLING AND ASSESSMENT}

Cell suspensions were incubated with the relevant monoclonal antibody at previously determined optimal concentrations for 30 minutes at $4^{\circ} \mathrm{C}$. This process was repeated with the appropriate label for unconjugated primary antibodies. Prior to flow cytometry (FACScan, Becton Dickinson, Belgium), labelled cells were washed twice and resuspended in $1 \%$ BFA and stored at $4^{\circ} \mathrm{C}$.

During flow cytometry, $10^{4}$ events were saved using Lysys II software (Becton Dickinson, Belgium). Because of overlapping cell populations based on forward and side scatter windows, total cell populations were scanned without the use of specific gates. The density of expression of surface antigens was measured as the change in the median fluorescence intensity (dMFI), using a logarithmic scale, of cells stained with specific antibody compared with the same cells stained with control antibody.

In a control experiment to test for altered cell membrane permeability, peripheral blood lymphocytes were isolated, incubated with $0.1 \% \mathrm{BFA}, 1 \% \mathrm{BFA}$ or $0.1 \%$ saponin and labelled with a monoclonal antibody to the intracellular antigen bcl-2. Positive staining was seen only with saponin treated cells (data not shown).

\section{STATISTICAL ANALYSIS}

Data were entered onto QuattroPro for Windows 5.0 (Borland Inc., USA) and statistical analyses performed using SPSS for Windows 6.0 (SPSS Inc., USA). The dMFI of medium only and BFA treated cells for each antibody was compared using the Wilcoxon rank sum 
test for paired non-parametric data. Correlation values are presented as the Pearson correlation co-efficient. For all analyses, significance was set at the $5 \%$ level.

\section{Results}

Cell yields for both medium only and BFA treated biopsy specimens were similar $(3.6 \pm 1.2 v 3.9 \pm 0.8$ million cells from three specimens). The presence of $0 \cdot 1 \%$ BFA during cell isolation resulted in enhanced detection of CD 45, CD11b, CD3, CD19, CD14, CD16, and CD63. However, this was at the expense of an increase in control antibody binding (table). The presence of BFA slightly diminished the intensity of fluorescence associated with both CD54 and CD67, although this did not reach statistical significance.

When compared with grade of macroscopic mucosal inflammation, several antigens correlated strongly with increasing score: $\mathrm{CD} 3$ $(\mathrm{r}=0.77, \quad \mathrm{p}<0.002) ; \quad \mathrm{CD} 11 \mathrm{~b} \quad(\mathrm{r}=0.72$, $\mathrm{p}<0.001)$; and CD54 ( $\mathrm{r}=0.73, \mathrm{p}<0.001)$. Results from the most intensely staining treatment group, medium only (CD54 and CD67) or BFA (CD11b, CD45, CD3, CD19, CD14, CD63, and CD16), were used to analyse each antigen.

\section{Discussion}

Flow cytometry provides a rapid method for the identification and screening of specific cell populations in heterogeneous suspensions. Solid tissues present particular difficulties, as they require both vigorous disaggregation and the use of proteolytic enzymes. Such stringent conditions can affect surface antigens through cleavage or changes in regulation. The use of fixatives in the processing of blood for flow cytometry has been reported. ${ }^{4}$ The results of our study show that such an approach is feasible with solid tissues; however, this is achieved at the expense of an increase in the level of binding of non-specific antibody. The finding that low concentrations of BFA did not render cells permeable is in keeping with other reports. ${ }^{6}$ Localised inflammation, as seen in inflammatory bowel disease, results from the sequential adhesion, activation and transmigration of leucocytes. ${ }^{7}$ During this process, surface antigens are altered both by translocation (CD11b, CD63, CD67) and de novo synthesis (CD54). ${ }^{8}$ We have found that fixation with $0 \cdot 1 \%$ BFA prior to flow cytometry enhances the detection of the neutrophil antigens CD11b, CD16 and CD63 and the monocyte/ granulocyte subset marker CD14. The low levels of CD16 detected are due to shedding of this glycosylphosphatidylinositol (GPI) linked molecule on neutrophil activation. ${ }^{9}$

Identification of the mixed populations present in mucosal specimens is complicated by the action of proteolytic enzymes on those antigens lacking a transmembrane domain-for example, those with GPI linkages. Several of the antigens probed in this study possess such a structure. The addition of BFA significantly enhanced the detection of both CD14 and CD16. However, this effect on GPI linked molecules was not uniform, as can be seen from results with CD67.

The close correlation between endoscopic mucosal appearance and prevalence of certain surface antigens (CD11b, CD54 and CD3) suggests that flow cytometry carried out on BFA treated cell suspensions derived from small numbers of biopsy specimens can yield useful results. The use of dual labelling would enhance the efficacy of such investigations, in particular, by enabling specific cell populations to be probed. However, the relative effect of BFA on each antigen needs to be quantified. The removal of epithelial cells would aid this process further, by reducing background autofluorescence. Importantly, the use of dilute BFA did not impair enzyme function, as measured by cell yield. This is of particular relevance to biopsy based studies as tissue quantities, and thus cell numbers, are limited.

In conclusion, the incorporation of dilute BFA during the enzymatic disaggregation of solid tissue provides a useful adjunct to the investigation of cellular surface antigens by flow cytometry. This particular application of BFA provides some degree of protection for such antigens and may prevent isolation related changes in their regulation.

1 Gibson PR, van de Pol E, Maxwell LE, Gabriel A, Doe WF. Isolation of colonic crypts that maintain structural and metabolic viability in vitro. Gastroenterology 1989;96:28391.

2 Roediger WEW, Truelove SC. Method of preparing isolated colonic epithelial cells (colonocytes) for metabolic studies. colonic epithelial cells

3 Springer TA. Traffic signals for lymphocyte recirculation and leukocyte emigration: the multi-step paradigm. Cell 1994; 76:301-14

4 Hamblin A, Taylor M, Bernhagen J, Shakoor Z, Mayall S, Noble G, McCarthy D. A method of preparing blood leucocytes for flow cytometry which prevents upregulation of leucocyte integrins. F Immunol Methods 1992;146:21928.

5 Baron JH, Connell AM, Lennard-Jones JE. Variations between observers in describing mucosal appearances in proctocolitis. BMf 1964;i:89-92.

6 Jacobberger JW. Intracellular antigen staining: quantitative immunofluorescence. Methods Enzymol 1991;2:207-18.

7 Adams DH, Shaw S. Leucocyte-endothelial interactions and regulation of leucocyte migration. Lancet 1994;343:831-6. 8 Wardlaw AJ, Walsh GM. Neutrophil adhesion receptors. In: Hellewell PG, Williams TJ, eds. Immunopharmacology of neutrophils. London: Academic Press, 1994:133-57.

9 Huizinga TWJ, de Haas M, van Oehrs MHJ, Kleijer M, Vile $\mathrm{H}$, van der Wouw PA, et al. The plasma concentration of soluble Fc-gamma RIII is related to production of neutrophils. $B r \mathcal{F}$ Haematol 1994;87:459-63. 